van PraAg, H. M. (1992) Reconquest of the subjective. Against the waning of psychiatric diagnosing. British Journal of Psychiatry. 160, 266-271.

Philip SNAITH

Academic Unit of Psychiatry

Clinical Sciences Building

St James's University Hospital

Leeds L59 $7 T F$

SIR: I read with interest Professor Cawley's article (Journal, February 1993, 162, 154-160). His emphasis on the presence of a "non-science dimension" within psychiatry is important and timely in view of the increasing emphasis on biologism in recent years. In addition, he suggests that the study of philosophy in relation to psychiatry may enable "orientation of the non-science aspects of psychiatry in the world of knowledge and thought".

I would like to suggest that much psychiatric thinking is already some way out of step with an important shift in scientific philosophy which reintroduces a sense of humanity into the scientific realm. The 'new physics' which has emerged in recent decades has had such an impact on the philosophy of scientific materialism (based on Newtonian mechanics) that physicists such as Paul Davies and John Gribben consider science to be moving into a new 'post-mechanistic' paradigm. Einstein's theory of relativity, which successfully challenged Newtonian concepts of space and time, was followed by quantum theory which changed our concept of the subatomic world from a simple deterministic one to a "shadowy and paradoxical conjunction of waves and particles governed by the laws of chance" (Davies \& Gribben, 1992). More recently, chaos theory has shown that 'non-linear' systems can become unstable and change in random and totally unpredictable ways. The implications of these discoveries are vast and will touch many disciplines. A whole new cosmology is emerging which places man firmly in the universe interacting intimately with it, rather than standing back as an aloof observer.

What are the implications for psychiatrists? Studies have started to appear in recent years applying the theory of chaos to such subjects as schizophrenia (Schmid, 1991), neurosynaptic transmission (Mandell, 1983), and the dynamics of psychotherapy (Lonie, 1991). In addition, the philosophical implications of this new 'post-mechanistic' science move away from positivism towards appreciation of the validity of non-scientific understandings of our world and ourselves. Perhaps most importantly, when we conceptualise ourselves within this novel scientific paradigm, we can no longer view ourselves in a reductionistic fashion. Human beings become more than biological machines. In fact the "highpriests' of science - the theoretical physicists-are telling us that we are no longer able to conceive the universe or ourselves as machine-like systems but rather as holistic, indeterministic open systems, vibrant with potentials and possessing infinite richness. It appears to me that such a view overlaps significantly with the six axioms which Professor Cawley describes as "primary features of human experience". In the view of today's theoretical physicists, Ryle (1990) was right to dismiss the notion of the "ghost in the machine" - "not because there is no ghost, but because there is no machine" (Davies \& Gribben, 1992).

I believe that these changes in thinking will not only validate the importance of Professor Cawley's 'nonscience' component, but will also incorporate aspects of it, such as the area of subjective experiences and inner life, into the science of the 21 st century.

Davies, P. \& Gribren, J. (1992) The Matter Myth: Beyond Chaos and Complexity. London: Penguin Books.

LONE, I. (1991) Chaos theory: a new paradigm for psychotherapy? Australian and New Zealand Journal of Psychiatry, 25(4), $548-560$.

MANDELL, A. J. (1983) From intermittency to transitivity in neuropsychobiological flows. American Journal of Physiology. 245(4), 484-494.

RYuE, G. (1990) The Concept of Mind. London: Penguin Books. SCHMD, G. B. (1991) Chaos theory and schizophrenia: elementary aspects. Psychopathology, 24(4), 185-198.

Northern General Hospital

JON LAUGHARNE

\section{Herries Road}

Sheffield S5 $7 A U$

\section{Ethnicity and relapse in schizophrenia}

SIR: I read with interest the paper by Birchwood et al (Journal, December 1992, 161, 783-790). They do not, however, refer to the study carried out at the Bethlem Royal and Maudsley Hospitals ('Joint Hospital'), an account of which was published the previous year (Gupta, 1991). Although the two studies do differ in a number of respects, many of their findings are similar. In both, for example, the Asian group had fewer readmissions to the hospital in question than the white group. Also the attrition rate at follow-up was greater in the former than in the latter (Gupta, 1992). What is not clear is whether these findings reflect differences in outcome or differences in the way in which different ethnic groups interact with medical and psychiatric services.

The social and family environment may of course affect both morbidity and service utilisation. Birchwood et al show that their Asian group were 